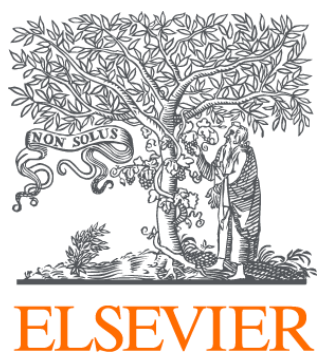

Since January 2020 Elsevier has created a COVID-19 resource centre with free information in English and Mandarin on the novel coronavirus COVID-

19. The COVID-19 resource centre is hosted on Elsevier Connect, the company's public news and information website.

Elsevier hereby grants permission to make all its COVID-19-related research that is available on the COVID-19 resource centre - including this research content - immediately available in PubMed Central and other publicly funded repositories, such as the WHO COVID database with rights for unrestricted research re-use and analyses in any form or by any means with acknowledgement of the original source. These permissions are granted for free by Elsevier for as long as the COVID-19 resource centre remains active. 
Regular article

\title{
Can youth empowerment programs reduce violence against girls during the COVID-19 pandemic?
}

\author{
Selim Gulesci ${ }^{\mathrm{a}}$, Manuela Puente-Beccar ${ }^{\mathrm{b}}$, Diego Ubfal ${ }^{\mathrm{c}, *}$ \\ a Trinity College Dublin, Ireland \\ ${ }^{\mathrm{b}}$ Bocconi University, Italy \\ ${ }^{c}$ Africa Region Gender Innovation Lab, World Bank, United States of America
}

\section{A R T I C L E I N F O}

\section{JEL classification:}

$\mathrm{J} 12$

J13

J16

O15

Keywords:

Youth empowerment

Violence against girls

List experiment

\begin{abstract}
A B S T R A C T
This paper shows that a youth empowerment program in Bolivia reduced the reported prevalence of violence against girls during the COVID-19 lockdown. The program offered training in soft skills and technical skills, sexual education, mentoring and job-finding assistance. To measure the effects of the program, the study conducted a randomized control trial with 600 vulnerable adolescents. Results indicate that 7 months after its completion, the program increased girls' earnings and decreased violence against girls. Violence was measured with both direct self-report questions and list experiments. These findings suggest that multi-faceted empowerment programs can reduce the level of violence experienced by young women during high-risk periods.
\end{abstract}

\section{Introduction}

Throughout the world, strict containment measures caused by the COVID-19 pandemic have increased risk factors associated with domestic violence. Media and institutional reports have indicated an increase of domestic violence and in particular of violence against women and children in countries affected by COVID-19 (e.g., Reynolds, 2020; Taub, 2020; Ritz et al., 2020). Several recent studies provide evidence of this by showing increases in violence against women (VAW) due to the COVID-19 pandemic and lockdown measures (Aguero, 2021; Boserup et al., 2020; Leslie and Wilson, 2020; Mahmud and Riley, 2021; Ravindran and Shah, 2020; Silverio-Murillo et al., 2021). The reported rise in VAW due to the COVID-19 pandemic has been named by UN Women as the "Shadow Pandemic" (United Nations Women, 2020).

In this paper, we study the effects of a youth empowerment program on the prevalence of violence against youth during the COVID-19 lockdown in Bolivia. The program combines training in soft skills and technical skills with sex education, mentoring and job-finding assistance. We conducted a randomized control trial with 600 vulnerable youth who applied to the program in four cities in Bolivia. Our data include an in-person baseline survey and a follow-up survey conducted by phone due the social distancing restrictions imposed by the COVID19 pandemic. The follow-up survey was carried out seven months after the end of the program and six months into the lockdown.

The program was designed to strengthen youth's income-generating capacity by developing their skills, and by offering job-finding assistance. Its main target outcomes were total earnings and soft skills. It was not designed to directly address violence against youth. However, given the alarming levels of violence reported at baseline, the increased relevance of violence against youth during the COVID-19 pandemic, and the possibility that both changes in soft skills and earnings could affect this outcome, we included violence as our third main outcome.

We find that the program significantly reduced violence experienced by treated girls. The prevalence of violence reported by girls fell by

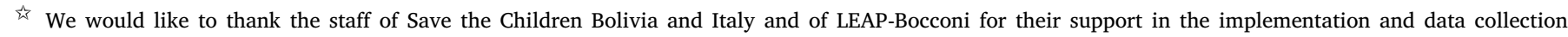

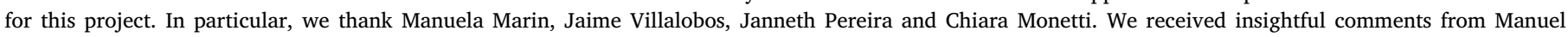

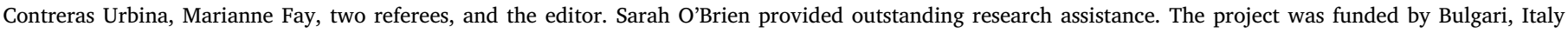

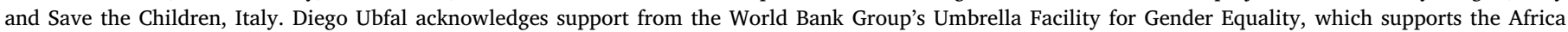

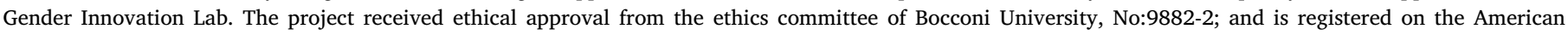

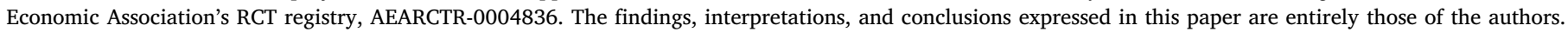

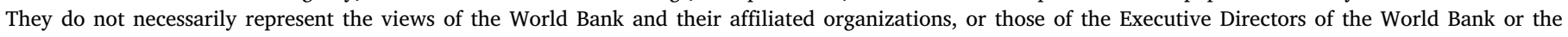
governments they represent.

* Corresponding author.

E-mail addresses: gulescis@tcd.ie (S. Gulesci), manuela.puente@unibocconi.it (M. Puente-Beccar), dubfal@worldbank.org (D. Ubfal). 
10 percentage points, over a mean of 21 percent in the control group. For boys, we do not find significant reductions in violence. To address concerns about self-reporting bias, we use item list experiments, which confirm our main findings. The level of violence among girls, as measured by a list experiment included in our follow-up survey, is much lower in the treatment group than in the control group, while it is not lower for treated boys than for control boys. We present evidence that the program had a positive effect on earnings for girls, but not for boys. This is consistent with an improvement in girls' bargaining power within the household or a reduction in income-related stress, both of which may explain the decrease in violence against girls. We do not find evidence for mechanisms related to changes in soft skills, as we do not see any effects of the program on a set of targeted soft skills.

The paper contributes to a burgeoning literature studying the causes of violence in general, and violence against girls in particular. Economic crises, conflicts and natural disasters are often linked to increased prevalence of violence against women and children (Anastario et al., 2013; Weitzman and Behrman, 2016; Fraser, 2020; Thurston et al., 2021). A recent study by Ravindran and Shah (2020) shows an increase in domestic violence complaints in India in districts with the strictest confinement rules. In a related study, Bandiera et al. (2020) show that temporary school closures during the 2014-16 Ebola epidemic in Sierra Leone increased teenage pregnancies and lowered school enrollment among girls, and a program that provided safe spaces (in the form of community clubs) and training in soft skills lowered these negative impacts. We contribute to this emerging literature by showing that multi-faceted youth empowerment programs can be one way to curtail the rise in violence against girls during high-risk periods, such as the COVID-19 pandemic and the ensuing lockdowns. ${ }^{1}$

The rest of the paper is organized as follows. Section 2 explains the details of the program. Section 3 describes the design of the experiment and sample characteristics. Section 4 presents the results. Section 5 discusses the results, and Section 6 concludes.

\section{Youth empowerment program}

The program Adolescents: Protagonists of Development has been implemented by the NGO Save the Children in Albania, Bolivia, Nepal and Uganda since 2016. Its main aim is to help vulnerable youth find a job, improve their working conditions and strengthen their income generation capacity. The target population consists of vulnerable adolescents aged 15 to 18 .

To identify the sample for this study, adolescents were recruited in four cities in Bolivia. Several recruitment strategies were used: fliers in markets and other public places, Facebook ads, cooperation with neighborhood associations and schools offering night shifts, and press conferences. Interested adolescents filled a form containing information used to measure their social vulnerability (e.g., housing conditions, access to health care, violence, substance use) and their economic vulnerability (e.g., household income, child labor, lack of economic support from the family). ${ }^{2}$ The program staff selected 600 adolescents that fulfilled at least one of the vulnerability criteria, giving priority to those with higher levels of vulnerability and who also showed willingness to participate in face-to-face interviews.

Table A2 compares key characteristics of the sample of recruited youth with those of a sample of youth aged 15-18, living in the four

\footnotetext{
1 See Kerr-Wilson et al. (2020) for a recent survey of interventions to prevent violence against women and girls. Our findings are in line with Yount et al. (2017), who conduct a systematic review of reviews on the impact of interventions to prevent violence against women and girls (VAWG) and conclude that bundled interventions with multiple components typically had more favorable impacts on VAWG than single-component interventions.

2 Table A1 presents the list of vulnerability criteria used by the program.
}

cities of our study, obtained from the representative Bolivian Household Survey. ${ }^{3}$ While we see similarities in some variables (television, computer and internet ownership and having children), and only a small difference in enrollment rates, it is clear that the study sample is more vulnerable as indicated by a higher probability of working, living in precarious dwellings, alcohol consumption, and being in a household with income below the minimum wage.

The program provided youth with soft skills and technical skills training, sex education, mentoring and support in finding a job or starting a business. In particular, it offered the following activities:

\section{- General Training}

- Personal empowerment (Module 1, 16 h)

- Sexual and reproductive health (Module 2, $16 \mathrm{~h}$ )

- Economic empowerment (Module 3, 16 h)

- Basic competences (Module 4, 16 h)

- Technical-skills training in predefined areas according to market demand $(70 \mathrm{~h})$

- Work insertion or business development

The four modules covering general training were taught by Save the Children. Module 1 focused on self-esteem and leadership while providing adolescents with an opportunity to get to know each other and increase trust. Module 2 discussed contraceptive methods and teen pregnancy. Module 3 covered material on market analysis, entrepreneurial soft skills, sustainable business models, workers' rights and how to prepare for a job interview. Finally, Module 4, taught basic math and literacy. These four modules were taught over the course of 4 four-hour sessions each.

After this general training, the project trained youth in specific technical skills. Participants selected up to three training courses from a menu designed based on market demand studies by Save the Children in cooperation with private partners in each region. The training was implemented by the local partners. For example, in La Paz, the most common choices were gastronomy, customer service and graphic design. The total length of these activities was approximately $70 \mathrm{~h}$.

The final activity of the project was to help adolescents find interviews with employers offering jobs that match adolescents' skill levels and satisfy certain standards (e.g., they are compatible with schooling, they do not involve risky activities, ${ }^{4}$ and they offer a wage no lower than the minimum wage $\mathrm{e}^{5}$ ). Working conditions were monitored for up to three months from the start of the jobs. The program also offered adolescents who did not want to find a job the opportunity to start their own business. However, this happened with only one adolescent in our sample.

\section{Methodology and sample characteristics}

\subsection{Methodology}

To estimate the effects of the program, we conducted a randomized controlled trial (RCT). The RCT was designed and implemented through our collaboration with Save the Children Bolivia and the support from Save the Children Italy. The evaluation covered four metropolitan cities in Bolivia: Cochabamba, La Paz, Oruro and Santa Cruz. The first step of the evaluation involved selecting a sample of eligible youth. The program team identified 600 youth satisfying the criteria for selection into the program as explained above. All selected youth completed an in-person baseline survey.

\footnotetext{
3 Source: Instituto Nacional de Estadistica (2019).

4 Under the Bolivian law, minors cannot work in certain tasks, such as mining or lifting heavy objects.

5 Informal employment is common in this context and minimum wage requirements are not strictly enforced for informal jobs.
} 
We then conducted a private lottery using Stata to randomly select 300 youth who would be offered to be part of the program starting from 2019 (treatment group), and 300 youth who would not be offered to be part of the program in 2019, but would have the chance to participate in the program after the evaluation (control group). When conducting the randomization, we stratified the samples on region, gender, age, whether the adolescent was working at the time of the interview and, only for Cochabamba and La Paz, ${ }^{6}$ whether s/he was a victim of violence.

The general training modules started in August 2019, and ran for approximately three months. The technical skills training was temporarily suspended during the election-related violence in October-November 2019, which translated into four weeks of highly reduced economic activity, but it was completed by December 2019 in all sites. In February 2020, the project started offering job-finding assistance. Due to the COVID-19 pandemic, the country entered a strict lockdown on March 22, 2020 (March 16 in Oruro). In two of the four cities (La Paz and Oruro), the program managed to offer job-finding assistance to most treated youth; while in the other two cities (Cochabamba and Santa Cruz), it only completed the training, with no significant job-finding assistance. In what follows, we assess the heterogeneity of treatment effects along this geographical dimension. ${ }^{7}$

Due to the COVID-related mobility restrictions, we conducted a follow-up survey by phone in the last two weeks of September $2020 .^{8}$ We were able to survey 511 adolescents (85\% of the sample). Response rates were similar across treatment arms, and we do not find any evidence of differential attrition (see Table A4 in the Appendix). ${ }^{9}$

Both the in-person baseline and the phone follow-up survey included a module to elicit sensitive questions on violence. To guarantee respondent's safety, enumerators were trained in each case by an expert on Child Safeguarding Policy following stringent ethical guidelines on how to ask these questions. Enumerators were instructed to take measures to verify the privacy of the interviews. Same-sex enumerators were used when possible. In the case of phone interviews, additional steps were taken to prevent potential perpetrators from listening to participants' answers. In particular, the interviewer provided examples of what types of actions are considered as violent; participants were asked to answer only "yes" or "no" and given the option of not answering the question if they did not feel comfortable with it. Respondents were also provided with a list of all the institutions where a violence victim can receive help and protection as well as the procedure to file a complaint (Appendix A.2 shows pictures of the material given to participants). Finally, enumerators received an adverse event protocol explaining what they had to do in cases of abuse.

${ }^{6}$ In Oruro and Santa Cruz there was not enough variation to stratify on violence.

7 Note that we are highly underpowered to detect regional heterogeneity of treatment effects by gender of the participants. As such, the analysis pertaining to regional heterogeneity should be seen as merely suggestive evidence.

8 Due to the pandemic, the country entered a strict lockdown in March 2020. Most of the population was forced to stay at home, except for those employed in priority sectors. In the beginning of June, some of the lockdown measures were relaxed and many economic activities restarted.

9 Due to the pandemic, we had to adapt our methodology relative to what we had pre-registered in the AEA's RCT registry. In particular, we had to switch from in-person to phone-based follow-up survey, which required using a shorter questionnaire than what we had originally planned. As a result, we were not able to collect detailed information on all the registered outcomes, such as youth's employment status. We decided to focus on outcomes that we deemed to be more relevant during the pandemic, such as violence, for which we introduced the list experiment.

\subsection{Sample characteristics}

Overall, $63 \%$ of the youth in the sample are girls. Table 1 presents summary statistics by gender on youth who completed both the baseline and follow-up surveys. Baseline characteristics of both boys and girls in the treatment and control samples are well balanced. ${ }^{10}$ Youth in the sample are 15 to 18 years old; around $65 \%$ of them are 17 or 18 years old.

The baseline data document a high level of violence experienced by both boys and girls. More than half of these youth reported having ever experienced some type of violence. Table A7 shows that most violence seemed to be happening at home: around a quarter of girls and boys affected by violence reported that the perpetrator was the father and/or the mother; $13 \%$ of boys and $20 \%$ of girls reported violence from siblings. This is in line with the finding in Devries et al. (2018) that the most common perpetrators of violence against both boys and girls are household members. However there is also an important role of violence perpetrated by friends (around 30\%) and other relatives ( $16 \%$ for boys and $9 \%$ for girls). Finally, $12 \%$ of boys and $9 \%$ of girls reported suffering violence from the partner, and $7 \%$ of girls and $4 \%$ of boys from teachers in school.

Violence is classified into 3 categories: physical, psychological, and sexual. ${ }^{11}$ Levels of physical and psychological violence are higher for boys, and the level of sexual violence is higher for girls. This high prevalence of violence is in line with that reported in other data sources in Bolivia (INE and UNICEF, 2005; UNICEF, 2014).

Average monthly earnings are higher for boys than for girls: Bs. 441 (64 USD) and Bs. 406 (59 USD), respectively. To put this in context, the national minimum wage during this period was Bs. 2,122 (307 USD) per month. In terms of sources of income, $26 \%$ of boys and $22 \%$ of girls receive some income from wage-employment, $3 \%$ of both girls and boys receive self-employment income, around $38 \%$ get informal transfers from family or friends and close to $2 \%$ get formal transfers from the government or an NGO. In order to measure soft skills, we used the "Employability Assessment (EA)" tool developed by Save the Children with the aim of measuring employability skills. The EA tool is a questionnaire with 24 items that produces quantitative scores for 6 categories of soft skills: self-concept, self-control, social skills, communication skills, conflict resolution skills and job-searching skills. $^{12}$

\subsection{Estimation of treatment effects}

In order to estimate the average treatment effects of the program, we use the following equation:

$y_{i}=\alpha+\beta \cdot T_{i}+\gamma \cdot T_{i} \cdot F_{i}+\lambda \cdot y_{i 0}+\Theta_{i 0}+\epsilon_{i t}$,

where $y_{i}$ is the outcome of interest for respondent $i$ at the followup survey, $T_{i}$ is a dummy variable equal to 1 if the respondent was allocated to the treatment group, $y_{i 0}$ is the baseline level of the outcome for individual $i, F_{i}$ is an indicator variable that is equal to 1 if the respondent is female and 0 otherwise, and $\Theta_{i 0}$ are randomization strata (dummies for each strata used in the randomization, including regional dummies). The estimate for $\beta$ corresponds to the treatment effect on males, the estimate for $\gamma$ correspond to the differential effect of the

\footnotetext{
10 Table A3 shows that the same holds for the full sample of youth who completed the baseline.

11 See Appendix 2 for details of the questions used to measure violence at baseline.

12 The detailed questions used in the tool are presented in Table A8. Each component of the index is constructed by first standardizing the responses to the individual questions (by subtracting the mean and dividing by the standard deviation of the control group) and then averaging across the standardized outcomes.
} 
Table 1

Baseline characteristics and balance, panel sample.

\begin{tabular}{|c|c|c|c|c|}
\hline & \multicolumn{2}{|l|}{ Boys } & \multicolumn{2}{|l|}{ Girls } \\
\hline & (1) & (2) & (3) & (4) \\
\hline & $\begin{array}{l}\text { Control } \\
\text { Mean }\end{array}$ & $\begin{array}{l}\overline{\text { Treatment-control }} \\
\text { Diff. }\end{array}$ & $\begin{array}{l}\text { Control } \\
\text { Mean }\end{array}$ & $\begin{array}{l}\text { Treatment-control } \\
\text { Diff. }\end{array}$ \\
\hline Age 17 or 18 & $\begin{array}{l}0.629 \\
(0.486)\end{array}$ & $\begin{array}{l}-0.029 \\
(0.072)\end{array}$ & $\begin{array}{l}0.658 \\
(0.476)\end{array}$ & $\begin{array}{l}-0.020 \\
(0.053)\end{array}$ \\
\hline Enrolled in school & $\begin{array}{l}0.927 \\
(0.261)\end{array}$ & $\begin{array}{l}-0.049 \\
(0.044)\end{array}$ & $\begin{array}{l}0.886 \\
(0.319)\end{array}$ & $\begin{array}{l}-0.019 \\
(0.037)\end{array}$ \\
\hline Any violence (ever) & $\begin{array}{l}0.515 \\
(0.502)\end{array}$ & $\begin{array}{l}0.018 \\
(0.073)\end{array}$ & $\begin{array}{l}0.500 \\
(0.502)\end{array}$ & $\begin{array}{l}0.018 \\
(0.056)\end{array}$ \\
\hline Physical & $\begin{array}{l}0.309 \\
(0.465)\end{array}$ & $\begin{array}{l}-0.032 \\
(0.067)\end{array}$ & $\begin{array}{l}0.278 \\
(0.450)\end{array}$ & $\begin{array}{l}-0.068 \\
(0.048)\end{array}$ \\
\hline Psychological & $\begin{array}{l}0.351 \\
(0.480)\end{array}$ & $\begin{array}{l}0.061 \\
(0.071)\end{array}$ & $\begin{array}{l}0.335 \\
(0.474)\end{array}$ & $\begin{array}{l}0.104 * \\
(0.054)\end{array}$ \\
\hline Sexual & $\begin{array}{l}0.021 \\
(0.143)\end{array}$ & $\begin{array}{l}0.002 \\
(0.021)\end{array}$ & $\begin{array}{l}0.057 \\
(0.233)\end{array}$ & $\begin{array}{l}0.009 \\
(0.027)\end{array}$ \\
\hline Income (last month) & $\begin{array}{l}441.278 \\
(782.309)\end{array}$ & $\begin{array}{l}-50.445 \\
(110.113)\end{array}$ & $\begin{array}{l}405.994 \\
(719.834)\end{array}$ & $\begin{array}{l}29.085 \\
(77.297)\end{array}$ \\
\hline Wage-emp. & $\begin{array}{l}0.258 \\
(0.440)\end{array}$ & $\begin{array}{l}-0.036 \\
(0.063)\end{array}$ & $\begin{array}{l}0.222 \\
(0.417)\end{array}$ & $\begin{array}{l}-0.041 \\
(0.045)\end{array}$ \\
\hline Self-emp. & $\begin{array}{l}0.031 \\
(0.174)\end{array}$ & $\begin{array}{l}-0.020 \\
(0.021)\end{array}$ & $\begin{array}{l}0.032 \\
(0.176)\end{array}$ & $\begin{array}{l}-0.008 \\
(0.018)\end{array}$ \\
\hline Informal transfer & $\begin{array}{l}0.361 \\
(0.483)\end{array}$ & $\begin{array}{l}0.050 \\
(0.072)\end{array}$ & $\begin{array}{l}0.392 \\
(0.490)\end{array}$ & $\begin{array}{l}0.053 \\
(0.055)\end{array}$ \\
\hline Formal transfer & $\begin{array}{l}0.021 \\
(0.143)\end{array}$ & $\begin{array}{l}-0.021 \\
(0.015)\end{array}$ & $\begin{array}{l}0.019 \\
(0.137)\end{array}$ & $\begin{array}{l}0.011 \\
(0.017)\end{array}$ \\
\hline Self concept & $\begin{array}{l}-0.092 \\
(0.609)\end{array}$ & $\begin{array}{l}0.003 \\
(0.091)\end{array}$ & $\begin{array}{l}0.049 \\
(0.675)\end{array}$ & $\begin{array}{l}0.013 \\
(0.080)\end{array}$ \\
\hline Self control & $\begin{array}{l}-0.089 \\
(0.676)\end{array}$ & $\begin{array}{l}-0.018 \\
(0.097)\end{array}$ & $\begin{array}{l}0.068 \\
(0.625)\end{array}$ & $\begin{array}{l}0.020 \\
(0.070)\end{array}$ \\
\hline Social skills & $\begin{array}{l}-0.149 \\
(0.714)\end{array}$ & $\begin{array}{l}-0.049 \\
(0.110)\end{array}$ & $\begin{array}{l}0.172 \\
(0.658)\end{array}$ & $\begin{array}{l}-0.119 \\
(0.076)\end{array}$ \\
\hline Communication skills & $\begin{array}{l}-0.085 \\
(0.788)\end{array}$ & $\begin{array}{l}0.014 \\
(0.107)\end{array}$ & $\begin{array}{l}0.041 \\
(0.723)\end{array}$ & $\begin{array}{l}-0.016 \\
(0.083)\end{array}$ \\
\hline Conflict resolution skills & $\begin{array}{l}-0.001 \\
(0.704)\end{array}$ & $\begin{array}{l}-0.049 \\
(0.103)\end{array}$ & $\begin{array}{l}0.075 \\
(0.671)\end{array}$ & $\begin{array}{l}-0.111 \\
(0.077)\end{array}$ \\
\hline Skills to look for a job & $\begin{array}{l}0.017 \\
(0.736)\end{array}$ & $\begin{array}{l}-0.054 \\
(0.110)\end{array}$ & $\begin{array}{l}0.037 \\
(0.764)\end{array}$ & $\begin{array}{l}-0.045 \\
(0.088)\end{array}$ \\
\hline Observations & 97 & 187 & 158 & 324 \\
\hline
\end{tabular}

Notes: The sample includes respondents who were successfully tracked and re-interviewed at the follow-up survey. Column (1) shows the mean and standard deviation for boys in the control group. Column (2) shows the coefficient of an OLS regression of each covariate on an indicator for treatment, robust standard errors are included in parentheses. Columns (3) and (4) show similar statistics for girls. The randomization was conducted within region and stratified on a dummy for age 17 or 18 (age 15 or 16 is the omitted category), a dummy for gender, for currently working and for reporting being victim of violence (only for Cochabamba and La Paz). * $p<0.10, * * p<0.05, * * * p<0.01$.

treatment on females relative to males, while the sum $\beta+\gamma$ corresponds to the treatment effect for females. We use standard errors that are robust to heteroskedasticity. For a few observations with missing values in the baseline value of the dependent variable, we replace those values with zero and add dummies for missing observations.

Our main table presents results for the three main outcomes: a dummy for any violence reported, monthly income and a soft skills index. We report p-values adjusted for the fact that we are testing for 6 main hypotheses ( 3 outcomes and 2 groups - boys and girls). ${ }^{13}$ We then look at more detailed variables for each of these outcomes: types of violence, sources of income and components of the soft-skill index.

\section{Results}

\subsection{Main outcomes}

Table 2 presents the effects of the program on the three main outcomes: reported violence in the 3 months before the survey, monthly income during the month before the survey and soft skills. We do

13 We obtain family-wise adjusted p-values using the implementation by Jones et al. (2018) of the free step-down procedure of Westfall and Young (1993). not see any statistically significant effect for boys. For girls, there is a marginally significant effect on monthly income and no effects on soft skills. We do see a significantly larger reduction in reported violence by girls, which survives the adjustment for multiple hypotheses testing. ${ }^{14}$ We study this effect in more detail below.

\subsection{Effects on violence: details}

Table 3 presents more details on the effects of the program on the prevalence of violence. In the follow-up survey, enumerators asked participants about violence experienced during the previous three months.

We find a negative and significant treatment effect on violence reported by girls, but not by boys. In particular, female participants are 9.5 percentage points (ppt) less likely to report suffering any violence. The point estimate for boys is positive $(7.2 \mathrm{ppt})$ but not statistically significant. The differential treatment effect on girls relative to boys is $16.8 \mathrm{ppt}$ and statistically significant. In terms of magnitudes, the $9.5 \mathrm{ppt}$

\footnotetext{
14 Our power calculations considering $15 \%$ attrition indicate that the minimum detectable effect to obtain $80 \%$ power at a $5 \%$ level is $0.21-0.22$ standard deviations of the outcome for the full sample, 0.26-0.28 s.d. for the subsample of girls and $0.34-0.37$ s.d. for the subsample of boys. Thus we are significantly underpowered to detect effects for boys.
} 
Table 2

Main outcomes.

\begin{tabular}{llll}
\hline & $\begin{array}{l}(1) \\
\text { Any violence } \\
\text { (last 3 months) }\end{array}$ & $\begin{array}{l}\text { (2) } \\
\text { Income (last } \\
\text { month) }\end{array}$ & $\begin{array}{l}\text { (3) } \\
\text { Soft skills } \\
\text { index }\end{array}$ \\
\hline Treat & 0.072 & -79.072 & 0.073 \\
& $(0.049)$ & $(100.555)$ & $(0.065)$ \\
& {$[0.435]$} & {$[0.683]$} & {$[0.540]$} \\
Treat $\times$ Female & $-0.168^{* * *}$ & 198.477 & -0.037 \\
& $(0.065)$ & $(121.704)$ & $(0.084)$ \\
& {$[0.050]$} & {$[0.338]$} & {$[0.659]$} \\
\hline Observations & 507 & 511 & 511 \\
Treatment effect for females & $-0.095^{* *}$ & $119.404^{*}$ & 0.036 \\
& $(0.042)$ & $(67.434)$ & $(0.053)$ \\
Control mean, male & {$[0.085]$} & {$[0.242]$} & {$[0.709]$} \\
Control mean, female & 0.073 & 539.794 & 0.027 \\
\hline
\end{tabular}

Notes: OLS regressions controlling for baseline value of the outcome and randomization strata. We replace missing values in covariates with zeros and include dummies for missing observations. Robust standard errors in parenthesis and p-values adjusted for multiple hypotheses testing in squared brackets. We adjust for 6 hypotheses ( 3 outcomes and 2 groups - males and females). At the bottom of the table we present the adjusted p-values for the effects for females, which is a linear combination of the other coefficients, and not a new hypothesis. "Control mean" refers to the mean in the control group of males/females at follow-up survey. Any violence: dummy variable equal to 1 if the respondent reported having experienced one of three types of violence during the 3 months preceding the follow-up survey (See Appendix A.1 for details). It is defined as missing if any of the answers for the different types of violence are missing. Income: total income the month before the follow-up survey, in Bolivianos. Soft Skills Index: index constructed out of 24 questions reported in Table A8 and a dummy variable $=1$ if the respondent overestimated the number of correct answers provided to five general knowledge questions. The stars are based on the p-values before adjusting for multiple hypotheses. * $p<0.10$, ** $p<0.05, * * * p<0.01$.

reduction in the prevalence of violence against girls in the treatment group is a large impact, corresponding to a $46 \%$ reduction relative to the control group where $21 \%$ of girls reported having experienced any type of violence.

The rest of Table 3 shows the effect on the different types of violence: physical, psychological and sexual. For girls, the program had a negative effect on all three types of violence, lowering the prevalence of physical violence by 3 ppt ( $56 \%$ relative to the control group), psychological violence by $10 \mathrm{ppt}$ (50\% reduction) and sexual violence by 3 ppt (103\% reduction). The effect on physical violence is imprecisely estimated at conventional levels, while the effects on psychological and sexual violence are statistically significant at the 95\% confidence level. We also find a marginally significant increase in psychological violence for treated boys. In particular, boys in the treatment group are $8 \mathrm{ppt}$ more likely to report having experienced any psychological violence relative to the control group. ${ }^{15}$

A potential concern with measuring sensitive topics, such as the prevalence of violence, through direct survey questions is reporting bias: respondents may not want to report violence due to shame or concerns about anonymity. To address this concern, a strategy commonly used in the literature is to rely on indirect elicitation techniques, such as list experiments (e.g., Rosenfeld et al., 2015). During the follow-up survey, we conducted a list experiment to elicit rates of violence among youth. In particular, respondents were asked to report the number of statements from a list of 4 or 5 items that applied to them. ${ }^{16}$ Every

15 The violence figures are not directly comparable to those reported at baseline. First, because the baseline survey was conducted in person, while the follow-up was conducted by phone. Second, because at baseline the question was about having ever suffered violence, while the follow-up asked about the past three months. See Appendix A.1 for details.

16 Respondents were read the following script: "Now I'm going to read some statements about many different things. Some of these statements will be true and some will not. After I read all statements, please tell me how many of them are true for you. I don't want to know which ones, just how many". respondent was randomly assigned to one of two groups (group A or group B). Respondents in group B were presented with a list of 4 items, which did not include any sensitive item; while respondents in group A were presented with a list of 5 items, one of which was the sensitive item. ${ }^{17}$ The only difference between the two lists was the presence of the statement "You have suffered some kind of physical violence in the last week" in the list presented to group A but not to group B. In order to calculate the percentage of youth for whom the sensitive item is true (i.e., the percentage of people who have suffered some kind of physical violence in the last week), we look at the difference between the average number of statements reported as true by respondents in group A relative to B. Since the assignment of individuals to group A or B is random, there is no reason why the number of true statements in the two groups should be different, other than the presence of the sensitive item. To ensure that the randomization was balanced within gender and treatment group, we randomized female and male respondents in treatment and control groups separately.

We conduct a number of validity checks for the list experiment. First, Table A5 in the Appendix shows that Group A and Group B are balanced in terms of their baseline characteristics within gender groups. Second, we chose items whose evaluation should not be affected by the inclusion of sensitive items. To formally test for the existence of design effects, we use the likelihood ratio test proposed by Blair and Imai (2012). Table 3, column 5, reports the $p$-value of this test, which is 1 . Thus we fail to reject the null hypothesis of no design effects. Third, the items in the list experiment were designed so that few respondents in the control group would answer affirmatively or negatively to all of them. Indeed, we observe few extreme responses: less than $10 \%$ of participants answered negatively or positively to all items. Therefore, floor or ceiling effects are unlikely to affect our results.

We run a linear regression of the number of correct statements on dummies for the randomly allocated group, treatment, female, all double interactions and the triple interaction among these variables. The last column of Table 3 reports the coefficient on the interaction between treatment and randomly allocated group (Treat), which captures the effect of treatment on physical violence for boys, and on the triple interaction between treatment, group and female (Treat X Female), which captures the differential treatment effect for girls. Two findings are of note: first, the rate of physical violence in the control group is $32 \%$ for boys and $39 \%$ for girls, which is much higher than those reported in the direct survey questions referring to even longer reference periods ( $6 \%$ for females and 3\% for males). One explanation of this difference is that participants tend to under-report sensitive questions when asked directly about the sensitive topic. Second, consistent with the direct survey question, the effect of the treatment in reducing violence is driven entirely by females, which is confirmed by a large interaction coefficient $(-50 \mathrm{ppt})$ significant at the $10 \%$ level. The effect for boys is an increase of $15 \mathrm{ppt}$, whereas the effect for girls is a reduction in 35 ppt, both coefficients are imprecisely measured.

Overall, results from the list experiment show a similar pattern as the direct questions in the survey: the program reduced the likelihood of experiencing violence among girls, but not among boys.

\subsection{Effect on violence: possible mechanisms}

There are several channels through which the program may have led to a reduction in the prevalence of violence among treated girls. In this section, we discuss and test for some of the key mechanisms that have been highlighted in the literature. We discuss other potential mechanisms which we, unfortunately, do not have information on, in the discussion section.

\footnotetext{
17 More specifically, respondents in group A were given the following 5 statements: "(1) You have been to Peru, (2) You can play the guitar, (3) You have a family member who lives in La Paz, (4) You have seen the movie Avengers: Endgame" and the sensitive item "(5) You have suffered some kind of physical violence in the last week"; while respondents in group B were only given the first 4 statements.
} 
Table 3

Violence.

\begin{tabular}{|c|c|c|c|c|c|}
\hline & \multicolumn{4}{|c|}{ Self reported (last 3 months) } & \multirow{3}{*}{$\begin{array}{l}\text { List exp. (last week) } \\
\text { (5) } \\
\text { Physical }\end{array}$} \\
\hline & $(1)$ & (2) & (3) & (4) & \\
\hline & Any violence & Physical & Psychological & Sexual & \\
\hline Treat & $\begin{array}{l}0.072 \\
(0.049)\end{array}$ & $\begin{array}{l}0.010 \\
(0.026)\end{array}$ & $\begin{array}{l}0.082^{*} \\
(0.049)\end{array}$ & $\begin{array}{l}0.019 \\
(0.023)\end{array}$ & $\begin{array}{l}0.149 \\
(0.268)\end{array}$ \\
\hline Treat $\times$ Female & $\begin{array}{l}-0.168^{* * *} \\
(0.065)\end{array}$ & $\begin{array}{l}-0.042 \\
(0.035)\end{array}$ & $\begin{array}{l}-0.185^{* * * *} \\
(0.063)\end{array}$ & $\begin{array}{l}-0.053^{*} \\
(0.028)\end{array}$ & $\begin{array}{l}-0.501 * \\
(0.296)\end{array}$ \\
\hline Observations & 507 & 511 & 508 & 510 & 507 \\
\hline Treatment effect for females & $\begin{array}{l}-0.095^{* *} \\
(0.042)\end{array}$ & $\begin{array}{l}-0.032 \\
(0.025)\end{array}$ & $\begin{array}{l}-0.103^{* *} \\
(0.042)\end{array}$ & $\begin{array}{l}-0.033^{* *} \\
(0.016)\end{array}$ & $\begin{array}{l}-0.353 \\
(0.235)\end{array}$ \\
\hline p-value no design effects & & & & & 1.000 \\
\hline Control mean, male & 0.073 & 0.031 & 0.063 & 0.021 & 0.320 \\
\hline Control mean, female & 0.210 & 0.057 & 0.209 & 0.032 & 0.391 \\
\hline
\end{tabular}

Notes: OLS regressions where the dependent variable is a dummy variables $=1$ if the respondent reported having experienced: in column (1) any violence during the 3 months preceding the follow-up survey defined as missing if any of the answers for the different types of violence are missing (See Appendix A.1 for details); in column (2) any physical violence, which "includes cases when someone hits or slaps you, or pushes or pulls your hair", in column (3) any psychological violence, which "includes cases when someone insults, threatens, verbally abuses, ridicules or makes fun of you", in column (4) any sexual violence, which "includes cases when someone touches your body without your permission, or forces you to have sex". The last column presents the results of the list experiment: respondents were randomly allocated to a group given 5 statements (including a sensitive item) or a group given 4 statements. The sensitive item was "You have suffered some kind of physical violence in the last week". We run a regression of number of correct statements on the randomly allocated group, treatment, a female dummy and all interactions among these variables. The table reports the coefficient on the interaction between treatment and group, and on the triple interaction among treatment, group and female. All regressions control for randomization strata and an indicator for having ever experienced the corresponding type of violence at baseline. The test for the presence of design effects is based on the likelihood ratio test proposed by Blair and Imai (2012). "Control mean" refers to the mean in the control group of males/females at follow-up survey. Robust standard errors in parentheses. ${ }^{*} p<0.10$, ${ }^{* *}$ $p<0.05, * * * p<0.01$.

\subsubsection{Effect on earnings}

To the extent that the program increased earnings for girls in the treatment group, this may have lowered the prevalence of violence against them through two mechanisms: First, a change in women's access to economic opportunities (such as employment or other earnings) may decrease or increase the prevalence of violence, depending on the initial allocation of bargaining power within the household and whose reservation utility is binding (Tauchen et al., 1991; Eswaran and Malhotra, 2011; Bloch and Rao, 2002; Anderson and Genicot, 2015). ${ }^{18}$ If the program increased girls' earnings, this could have improved their outside options within the household and enabled them to leave abusive relationships. Second, economic insecurity and poverty-related stress caused by the lockdown measures are likely to increase the risk of domestic violence towards women and children (Peterman and O'Donnel, 2020; Conrad-Hiebner and Byram, 2020). An increase in earnings due to participation in the program may have mitigated the higher stress levels linked to economic insecurity and lowered the prevalence of violence.

Table 2 shows that girls in the treatment group earned Bs. 119 more than girls in the control group and this effect is significant at the $10 \%$ level. Compared to the mean income of females in the control group (Bs. 294), this corresponds to a $41 \%$ increase in total income. We have to be cautious because if we consider that income was one of our three main outcomes and adjust for multiple hypotheses correction, the effect loses statistical significance.

Table 4 tests if the program affected the different sources of income. Given the short length of the phone survey, we only have information on the extensive margin of these sources and not the value of earnings from each source. We find that treated girls are $8 \mathrm{ppt}$ less likely to report earnings from wage labor. They are $2 \mathrm{ppt}$ more likely to report having income from self-employment and $3.5 \mathrm{ppt}$ more likely to have earnings from formal transfers (government or NGO provided),

\footnotetext{
18 The existing evidence on the effects of labor market opportunities and income of women relative to men on the prevalence of domestic violence is mixed (Aizer, 2010; Andenberg et al., 2016; Angelucci, 2008; Bhalotra et al., 2021; Bobonis et al., 2013; Chin, 2012; Heath, 2014; Heise and Kotsadam, 2015; Hidrobo and Fernald, 2013).
}

but these effects are imprecisely estimated. We cannot identify which source is driving the increase in earnings of females reported in column (1).

Tables A6 presents results on the regional heterogeneity of the treatment effects on the three main outcomes. We find that the treatment effects for females on both violence and earnings are concentrated on the Cochabamba/Santa Cruz subsamples, as opposed to La Paz/Oruro. This supports the idea that in places where the program succeeded in increasing girls' earnings, it also led to a reduction in the prevalence of violence targeting them. Moreover, this provides additional evidence that the increase in earnings is not linked to the job-finding assistance provided by the program, since Cochabamba and Santa Cruz were precisely the two regions where the program did not manage to offer this type of assistance as noted in Section 3.1 above.

Overall, the results in Table 4 provide some evidence that the program helped girls increase their income, even if it was not through helping them find a better job as originally planned. This increase in girls' earnings may explain why they experienced lower violence - either because of their improved bargaining power within the household; or because the higher earnings lowered the prevalence of stress-related violence against girls.

\subsubsection{Effects on soft skills}

To the extent that the program succeeded in changing girls' soft skills, such as self-confidence and expressiveness, this may have empowered them to leave or better face abusive relationships. Table 5 presents more details on the treatment effects on soft skills.

Overall, we do not find significant effects on soft skills - the aggregate index combining the seven standardized indices included in the table shows no significant treatment effect (column 1), neither for boys nor for girls. When we examine the effects on individual components of the index, we only see significant treatment effects for girls in one of the seven soft-skills indices - that on job-searching skills. Column (8) of Table 5 reports the effects on a task we added in the follow-up survey to measure self-confidence. ${ }^{19}$ The program has

19 This task is a simplified, non-incentivized version of that developed in Blavatskyy (2009). Respondents were asked five general knowledge questions: 
Table 4

Income.

\begin{tabular}{llllll} 
& \multicolumn{5}{l}{ Income source } \\
\cline { 3 - 6 } & $(1)$ & $(2)$ & $(3)$ & $(4)$ & $(5)$ \\
& Income (last month) & Wage-emp. & Self-emp. & Informal transfer & Formal transfer \\
\hline Treat & -79.072 & -0.006 & $0.058^{*}$ & 0.017 & -0.016 \\
& $(100.555)$ & $(0.062)$ & $(0.032)$ & $(0.061)$ & $(0.057)$ \\
Treat $\times$ Female & 198.477 & -0.072 & -0.041 & -0.008 & 0.048 \\
& $(121.704)$ & $(0.076)$ & $(0.043)$ & $(0.075)$ & $(0.068)$ \\
\hline Observations & 511 & 511 & 511 & 511 & 511 \\
Treatment effect for females & $119.404^{*}$ & $-0.078^{*}$ & 0.017 & 0.009 & 0.032 \\
& $(67.434)$ & $(0.043)$ & $(0.029)$ & $(0.044)$ & $(0.037)$ \\
Control mean, male & 539.794 & 0.289 & 0.021 & 0.206 & 0.165 \\
Control mean, female & 294.114 & 0.234 & 0.057 & 0.203 & 0.120 \\
\hline
\end{tabular}

Notes: OLS regressions. The dependent variable in column (1) is total income of the respondent during August 2020, the month before the follow-up survey, in Bolivianos. The dependent variables in columns (2)-(5) are dummy variables $=1$ if the respondent had any earnings from wage-employment, self-employment, informal transfers (from family or friends) or formal transfers (from the government or NGOs), respectively. All regressions control for randomization strata and the baseline value of the dependent variable. "Control mean" refers to the mean in the control group of males/females at follow-up survey. Robust standard errors are presented in parentheses. ${ }^{*} p<0.10,{ }^{* *} p<0.05,{ }^{* * *} p<0.01$.

Table 5

Soft skills.

\begin{tabular}{|c|c|c|c|c|c|c|c|c|}
\hline & $\begin{array}{l}\text { (1) } \\
\text { Soft skills } \\
\text { aggregate index }\end{array}$ & $\begin{array}{l}\text { (2) } \\
\text { Self concept }\end{array}$ & $\begin{array}{l}\text { (3) } \\
\text { Self control }\end{array}$ & $\begin{array}{l}\text { (4) } \\
\text { Social skills }\end{array}$ & $\begin{array}{l}\text { (5) } \\
\text { Communication } \\
\text { skills }\end{array}$ & $\begin{array}{l}6) \\
\text { Conflict } \\
\text { resolution }\end{array}$ & $\begin{array}{l}\text { (7) } \\
\text { Job search } \\
\text { skills }\end{array}$ & $\begin{array}{l}\text { (8) } \\
\text { Confidence }\end{array}$ \\
\hline Treat & $\begin{array}{l}0.073 \\
(0.065)\end{array}$ & $\begin{array}{l}0.033 \\
(0.105)\end{array}$ & $\begin{array}{l}0.008 \\
(0.086)\end{array}$ & $\begin{array}{l}0.044 \\
(0.109)\end{array}$ & $\begin{array}{l}0.015 \\
(0.093)\end{array}$ & $\begin{array}{l}-0.038 \\
(0.098)\end{array}$ & $\begin{array}{l}0.047 \\
(0.096)\end{array}$ & $\begin{array}{l}0.178^{* * *} \\
(0.069)\end{array}$ \\
\hline Treat $\times$ Female & $\begin{array}{l}-0.037 \\
(0.084)\end{array}$ & $\begin{array}{l}0.011 \\
(0.133)\end{array}$ & $\begin{array}{l}-0.026 \\
(0.108)\end{array}$ & $\begin{array}{l}-0.110 \\
(0.136)\end{array}$ & $\begin{array}{l}0.005 \\
(0.124)\end{array}$ & $\begin{array}{l}0.049 \\
(0.129)\end{array}$ & $\begin{array}{l}0.221 * \\
(0.124)\end{array}$ & $\begin{array}{l}-0.184^{* *} \\
(0.090)\end{array}$ \\
\hline Observations & 511 & 511 & 511 & 511 & 511 & 511 & 511 & 511 \\
\hline Treatment effect for females & $\begin{array}{l}0.036 \\
(0.053)\end{array}$ & $\begin{array}{l}0.044 \\
(0.081)\end{array}$ & $\begin{array}{l}-0.018 \\
(0.065)\end{array}$ & $\begin{array}{l}-0.066 \\
(0.080)\end{array}$ & $\begin{array}{l}0.020 \\
(0.081)\end{array}$ & $\begin{array}{l}0.010 \\
(0.083)\end{array}$ & $\begin{array}{l}0.268^{* * *} \\
(0.079)\end{array}$ & $\begin{array}{l}-0.006 \\
(0.057)\end{array}$ \\
\hline Control mean, male & 0.027 & 0.029 & -0.010 & -0.042 & 0.015 & 0.031 & 0.141 & 0.546 \\
\hline Control mean, female & -0.019 & -0.018 & 0.006 & 0.026 & -0.009 & -0.019 & -0.086 & 0.519 \\
\hline
\end{tabular}

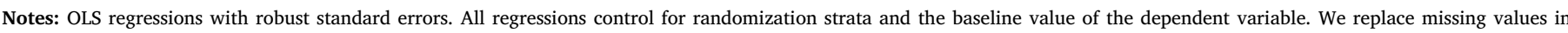

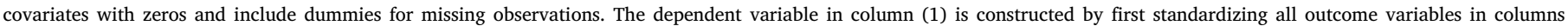

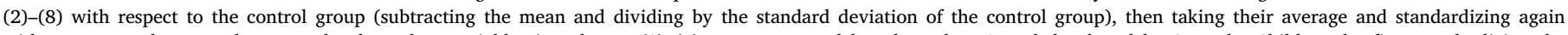

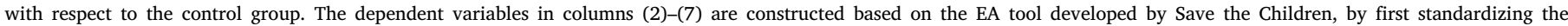

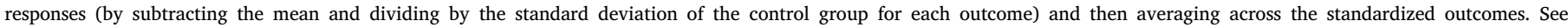

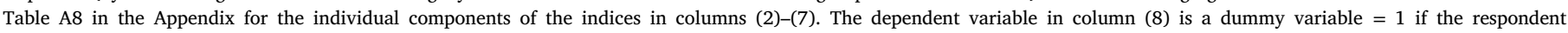

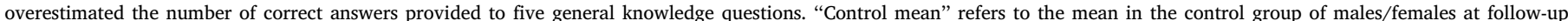
survey. $* p<0.10, * * p<0.05, * * * p<0.01$.

an effect on self-confidence only for boys. While $55 \%$ of boys in the control group are classified as over-confident, this share increases by 18 percentage points in the treatment group. For girls, we see a similar share of $52 \%$ classified as over-confident in both treatment and control groups (we do not see any effects for girls on being classified as underconfident either). Overall, the evidence suggests that the program did not have a significant effect on soft skills. This could be because soft skills are in general hard to measure, and the methods we used in the phone survey are not ideal to capture changes in soft skills.

As noted in Section 4.2, we find a small increase in the prevalence of psychological violence among boys in the treatment group. This may be linked to the increase in boys' overconfidence caused by the program. One hypothesis is that as they became more confident, boys may have tried to assert their opinions more strongly in their households or social networks, leading to an increase in arguments and verbal clashes. An alternative explanation could be that the program did not lead to an increase in boys' earnings and this may have increased verbal abuse and conflict with their families or friends.

"(1) How many strings does an electric guitar have, (2) What country is Bad Bunny from?, (3) What kingdom do mushrooms belong to?, (4) What was the profession of Vincent van Gogh?, (5) What is the capital of Colombia?' Then, they had to guess how many of these questions they answered correctly. Overestimating the number of correct answers is taken as an indirect measure of overconfidence.

\section{Discussion}

Our findings indicate that a multi-faceted program designed to strengthen youth's income generating capacity can have significant downstream effects on reducing violence against girls. This finding is in line with the evidence presented in the review by Yount et al. (2017), which concludes that bundled interventions with multiple components show more favorable effects on violence against women and girls than single-component interventions. The intervention we evaluate combines various components aimed towards improving skills, agency and social networks. Future work should study how to build the package of interventions that is most effective to reduce the prevalence of violence.

Our analysis provides some evidence that the program increased girl's earnings, which could have improved their outside options and their economic empowerment. But there are alternative mechanisms through which the program may have diminished the prevalence of violence against girls. One is by lowering exposure to abusers. Confinement measures may put women and children living in abusive relations at even greater risk of violence because of increased exposure to their abusers. Exposure theories suggest that when perpetrators spend more time outside the home, victims are less exposed to potential abuse (Chin, 2012; Mobarak and Ramos, 2020). If the program decreased girls' chances of being exposed to their abusers during the lockdown (for instance, if they were more likely to have jobs in the "priority sectors" that were allowed to remain open or if the youth were able to find safer housing away from the perpetrators of violence), this may 
have reduced violence within the treatment group. However, we do not have any evidence that points in that direction. Another alternative mechanism could be improvements in girls' knowledge of and access to support services. To the extent that the program succeeded in providing support to girls in the treatment group that experienced violence prior to the lockdown, this may have increased their knowledge of and access to support services. Their abusers may have also become more aware of girls' improved access to support in case of violence. Unfortunately, we do not have any information to test this mechanism. The information we have indicates that the program did put in contact with support services those adolescents who reported abuse at baseline, but it did so equally in the treatment and control groups. Another mechanism might be improved social capital. The youth may have built better support networks during the program and this could have offered them an avenue to cope with or combat violence during the pandemic. These are all potential mechanisms that are worth exploring in future research evaluating youth empowerment programs.

\section{Conclusions}

In this paper, we present results on the effects of a multi-faceted youth empowerment program in Bolivia. We find that the program significantly reduced violence reported by girls during the lockdown period. While we do not have strong evidence on the mechanisms that generated this effect, we see some weak evidence for an increase on girls' earnings that are coming from activities unrelated to wage work. This increase in earnings could have improved girls' outside options and their economic empowerment and played a role in the reduction in violence against them.

The main contribution of our study is to show that multi-faceted interventions aiming to empower vulnerable youth can be particularly effective in reducing violence against girls (but not boys) during periods of heightened risk, such as the COVID-19 pandemic. Many studies have provided evidence of a sharp increase in violence against girls and women during the COVID-19 pandemic, but to our knowledge, this is the first paper reporting causal evidence of an intervention that significantly reduced violence against girls during the COVID-19 pandemic.

\section{CRediT authorship contribution statement}

Selim Gulesci: Conceptualization, Data curation, Formal analysis, Funding acquisition, Investigation, Methodology, Project administration, Resources, Supervision, Validation, Visualization, Writing - original draft, Writing - review \& editing. Manuela Puente-Beccar: Conceptualization, Data curation, Formal analysis, Investigation, methodology, Project administration, Resources, Supervision, Validation, Visualization, Writing - original draft, Writing - review \& editing. Diego Ubfal: Conceptualization, Data curation, Formal analysis, Funding acquisition, Investigation, Methodology, Project administration, Resources, Supervision, Validation, Visualization, Writing - original draft, Writing - review \& editing.

\section{Appendix A. Supplementary data}

Supplementary material related to this article can be found online at https://doi.org/10.1016/j.jdeveco.2021.102716.

\section{References}

Aguero, Jorge M., 2021. COVID-19 and the Rise of Intimate Partner Violence. World Dev. 137, 105217.

Aizer, A., 2010. The Gender Wage Gap and domestic violence. Amer. Econ. Rev. 100, 1847-1859.

Anastario, M., Shehab, N., Lawry, L., 2013. Increased gender-based violence among women internally displaced in mississippi 2 years Post-Hurricane Katrina. Disaster Med. Public Health Preparedness 3 (1), 18-26.
Andenberg, D., Rainer, H., Wadsworth, J., Wilson, T., 2016. Unemployment and domestic violence: Theory and evidence. Econom. J. 126, 1947-1979.

Anderson, S., Genicot, G., 2015. Suicide and property rights in India. J. Dev. Econ. 114, 64-78.

Angelucci, M., 2008. Love on the rocks: Domestic violence and alcohol abuse in rural Mexico. BE J. Econ. Anal. Policy 8 (1), 1-43.

Bandiera, O., Buehren, N., Goldstein, M., Rasul, I., Smurra, A., 2020. Do School Closures During an Epidemic Have Persistent Effects? Evidence from Sierra Leone in the Time of Ebola. Working Paper, UCL.

Bhalotra, S., Kambhampati, U., Rawlings, S., Siddique, Z., 2021. Intimate partner violence: The influence of Job Opportunities for Men and Women. World Bank Econ. Rev. 35 (2), 461-479.

Blair, G., Imai, K., 2012. Statistical analysis of list experiments. Political Anal. 20, 47-77.

Blavatskyy, P.R., 2009. Betting on own knowledge: Experimental test of overconfidence. J. Risk Uncertain. 38, 39-49.

Bloch, F., Rao, V., 2002. Terror as a Bargaining Instrument: A case study of dowry violence in rural India. Amer. Econ. Rev. 92 (4), 1029-1043.

Bobonis, G.J., Gonzalez-Brenes, M., Castro, R., 2013. Public transfers and domestic violence: The roles of private information and spousal control. Am. Econ. J.: Econ. Policy 5 (1), 179-205.

Boserup, B., McKenney, M., Elkbuli, A., 2020. Alarming trends in US domestic violence during the COVID-19 Pandemic. Am. J. Emerg. Med. 38 (12), 2753-2755.

Chin, Y.M., 2012. Male backlash, bargaining, or exposure reduction?: Women's working status and physical spousal violence in India. J. Popul. Econ. 25 (1), 175-200.

Conrad-Hiebner, A., Byram, E., 2020. The temporal impact of economic insecurity on child maltreatment: A systematic review. Trauma Violence Abuse 21 (1), 157-178.

Devries, K., Knight, L., M., Petzold., et al., 2018. Who perpetrates violence against children? A systematic analysis of age-specific and sex-specific data. BMJ Paediatr. Open 2 (1).

Eswaran, M., Malhotra, N., 2011. Domestic violence and women's autonomy in developing countries: theory and evidence. Canad. J. Econ. 44 (4), 1222-1263.

Fraser, E., 2020. Impact of COVID-19 Pandemic on Violence Against Women and Girls. Helpdesk Research Report No. 284, VAWG Helpdesk, London, UK.

Heath, R., 2014. Women's access to labor market opportunities, control of household resources, and domestic violence: Evidence from Bangladesh. World Dev. 57, 32-46.

Heise, L.L., Kotsadam, A., 2015. Cross-national and multilevel Correlates of Partner Violence: An analysis of data from population-based surveys. Lancet Glob. Health 3 (6), 332-340.

Hidrobo, M., Fernald, L., 2013. Cash transfers and domestic violence. J. Health Econ. 32 (1), 304-319.

INE and UNICEF, 2005. Violencia contra le niñez en Bolivia, La Paz - Bolivia. Instituto Nacional de Estadistica and United Nations Children's Fund.

Instituto Nacional de Estadistica, 2019. Encuesta de Hogares. Catalago de Microdatos. Instituto Nacional de Estadistica de Bolivia, http://anda.ine.gob.bo/index.php/ catalog/84.

Jones, D., Molitor, D., Reif, J., 2018. What Do Workplace Wellness Programs Do? Evidence from the Illinois Workplace Wellness Study. Working Paper 24229, NBER.

Kerr-Wilson, A., Gibbs, A., McAslan Fraser, E., Ramsoomar, L., Parke, A., Khuwaja, H.M.A., Jewkes, R., 2020. A rigorous global evidence review of interventions to prevent violence against women and girls. What Works to prevent violence among women and girls global Programme. Pretoria, South Africa.

Leslie, E., Wilson, R., 2020. Sheltering in place and domestic violence: Evidence from calls for service during COVID-19. J. Public Econ. 189, 104241.

Mahmud, M., Riley, E., 2021. Household response to an extreme shock: Evidence on the immediate impact of the Covid-19 lockdown on Economic Outcomes and Well-being in Rural Uganda. World Dev. 140, 105318.

Mobarak, M., Ramos, A., 2020. The Effects of Migration on Intimate Partner Violence: Evidence for Exposure Reduction Theory in Bangladesh. Working paper, Unpublished.

Peterman, A., O'Donnel, M., 2020. COVID-19 and Violence Against Women and Children: A Second Research Round Up. CGD Note 2020, Center for Global Development.

Ravindran, S., Shah, M., 2020. Unintended Consequences of Lockdowns: COVID-19 and the Shadow PandEmic. Working Paper 27562, NBER.

Reynolds, P., 2020. 25\% rise in domestic violence calls during pandemic. https: //www.rte.ie/news/2020/0609/1146245-domestic-violence-gardai/.

Ritz, D., O'Hare, G., Burges, M., 2020. The Hidden Impact of COVID-19 on Child Protection and Wellbeing. Save the Children International., London.

Rosenfeld, B., Imai, K., Shapiro, J.N., 2015. An empirical validation study of popular survey methodologies for sensitive questions. Am. J. Political Sci. 60 (3), 783-802.

Silverio-Murillo, A., Balmori de la Miyar, J.R., Hoehn-Velasco, L., 2021. Families under Confinement: COVID-19, Domestic Violence. Andrew Young School of Policy Studies Research Paper Series..

Taub, A., 2020. A New Covid-19 Crisis: Domestic Abuse Rises Worldwide. New York Times, 6 April. https://www.nytimes.com/2020/04/06/world/coronavirusdomestic-violence.html.

Tauchen, H., Witte, A., Long, S., 1991. Domestic violence: A nonrandom affair. Internat. Econom. Rev. 32 (2), 491-511. 
Thurston, A.M., Stöckl, H., Ranganathan, M., 2021. Natural hazards, disasters and violence against women and girls: a global mixed-methods systematic review. BMJ Glob. Health 6 (4).

UNICEF, 2014. Hidden in Plain Sight: A statistical analysis of violence against children. United Nations Children's Fund.

United Nations Women, 2020. COVID-19 and Ending Violence Against Women and Girls. UN Women.
Weitzman, A., Behrman, J.A., 2016. Disaster, disruption to family life and intimate partner violence: The case of the 2010 earthquake in haiti. Sociol. Sci. 3, 167-189. Westfall, P.H., Young, S.S., 1993. Resampling-Based Multiple Testing: Examples and Methods for $P$-Value Adjustment. John Wiley \& Sons.

Yount, K.M., Krause, K.H., Miedema, S.S., 2017. Preventing gender-based violence victimization in adolescent girls in lower-income countries: Systematic review of reviews. Soc. Sci. Med. 192, 1-13. 